\title{
Anti-hypertensive effect of Morus alba L extract in rats
}

\author{
Sheng-li Pei ${ }^{1}$, Fang Kan², Chun-jiang Yue ${ }^{3 *}$ \\ ${ }^{1}$ Nursing Department, ${ }^{2}$ Department of Neurosurgery, ${ }^{3}$ Department of Vasculocardiology, Tongren Hospital Affiliated to Wuhan \\ University (The Third Hospital of Wuhan), Wuhan 430060, Hubei Province, China
}

*For correspondence: Email: 1350794936@qq.com; Tel: +86 13971128500

Sent for review: 25 September 2020

Revised accepted: 22 May 2021

\begin{abstract}
Purpose: To investigate the probable antihypertensive effects of Morus alba L. extract (MALE) in renovascular hypertensive rats, and the mechanism involved in the reduction of blood pressure.

Methods: The two-kidney one-clip (2K1C) Goldblatt model of renovascular hypertension was used in Wistar rats. The $2 \mathrm{~K} 1 \mathrm{C}$ group rats were treated with captopril $(30 \mathrm{mg} / \mathrm{kg})$, and Morus alba extract (75 and $150 \mathrm{mg} / \mathrm{kg}$ ) daily for 6 weeks by intragastric administration. Systolic (SBP) and diastolic blood pressure $(D B P)$ were measured by the tail-cuff method. Urine creatinine and urea of the rats were measured by enzyme-linked immunosorbent assay (ELISA). Superoxide dismutase (SOD) and malondialdehyde (MDA) were also evaluated using standard techniques.

Results: In the captopril- and extract-treated groups, blood pressure decreased progressively over the course of the 6-week treatment period compared with that of the control rats $(p<0.01)$. The extract at $150 \mathrm{mg} / \mathrm{kg}$ also significantly $(p<0.05)$ increased plasma SOD activity but decreased plasma MDA concentration. Renal function significantly $(p<0.01)$ improved following captopril and extract $(150$ $\mathrm{mg} / \mathrm{kg}$ ) treatment.

Conclusion: The results suggest that Morus alba extract exerts its antihypertensive effect in rats by inhibiting endothelin (ET)-converting enzyme and via its antioxidant activity. Thus, the plant extract has some potentials for development into a new drug in ffor use in humans.
\end{abstract}

Keywords: Antihypertensive, Morus alba, Goldblatt renovascular hypertension, Endothelin-1, Hypertrophy

This is an Open Access article that uses a fund-ing model which does not charge readers or their institutions for access and distributed under the terms of the Creative Commons Attribution License (http://creativecommons.org/licenses/by/4.0) and the Budapest Open Access Initiative (http://www.budapestopenaccessinitiative.org/read), which permit unrestricted use, distribution, and reproduction in any medium, provided the original work is properly credited.

Tropical Journal of Pharmaceutical Research is indexed by Science Citation Index (SciSearch), Scopus, International Pharmaceutical Abstract, Chemical Abstracts, Embase, Index Copernicus, EBSCO, African Index Medicus, JournalSeek, Journal Citation Reports/Science Edition, Directory of Open Access Journals (DOAJ), African Journal Online, Bioline International, Open-J-Gate and Pharmacy Abstracts

\section{INTRODUCTION}

Hypertension is the most common risk factor for myocardial infarction, stroke, heart failure, arterial fibrillation, aortic dissection and peripheral arterial diseases [1]. It is among the most common chronic illnesses in the world [2] and remains the leading cause of death worldwide and one of the world's greatest public health problems. Although many new antihypertensive drugs with improved efficacy have been introduced to the market, they still possess serious side effects. Nutrition and physical exercises are gaining more importance in the treatment of hypertension. Recently interest have been focused on herbal and mineral preparations which are used traditionally as potential therapeutic agents in the prevention and management of cardiovascular diseases. 
The Goldblatt chronic two-kidney, one-clip hypertension $(2 \mathrm{~K} 1 \mathrm{C})$ is a classical model of renovascular angiotensin-Il-dependent hypertension. Experimental model of renal (Goldblatt) hypertension is one of the widely used models for the study of pathophysiology of hypertension and antihypertensive drugs [3,4]. The fact that the rennin-angiotensin system (RAS) contributes critically to the pathophysiology of $2 \mathrm{~K} 1 \mathrm{C}$ Goldblatt hypertension is well established [5]. The $2 \mathrm{~K} 1 \mathrm{C}$ model, which exhibits a transient increase in the activity of RAS and a sustained rise in blood pressure, has been described as very close to human mature hypertension $[6,7]$. Thus, hypertension in this model is primarily the result of an augmented total peripheral resistance and, in mild cases of renal artery stenosis, bilateral reduction in renalclearance function [8]. These physiological abnormalities are principally the result of a considerable increase in tissue and circulating levels, and direct actions of Ang-II [9]. Evidence shows that as the condition advances, the role of Ang-II in maintaining hypertension subsides, and other mediators become more effective in determining the level of blood pressure [10].

The study investigated the probable antihypertensive effects of Morus alba $L$. extract (MALE) in renovascular hypertensive rats as well as the mechanism involved in the reduction of blood pressure.

\section{EXPERIMENTAL}

\section{Collection and extraction of plant material}

The herbal material, Morus alba L. was collected from Shiyan City, Hubei Province in China in October 2020. Taxonomic identification of the plant was performed by Professor Jun Yang of college of pharmacy of Wuhan University, Wuhan, China. A voucher specimen (no. MALE 202010006) was deposited in the herbarium of College of Pharmacy, Wuhan University, China for future reference.

The leaf of Morus alba $L$. was dried in an oven at $80^{\circ} \mathrm{C}$ and macerated in water at $60^{\circ} \mathrm{C}$ for three times, each time for $1 \mathrm{~h}$. Then the extract was first dried in an oven at $80{ }^{\circ} \mathrm{C}$ and then freezedried to obtained MALE.

Induction of renovascular hypertension (twokidney, one-clip model)

Goldblatt 2K1C model of hypertension was induced according to the procedure described by Umar et al [11]. Briefly, the rats were anesthetized with sodium pentobarbital (50 $\mathrm{mg} / \mathrm{kg}$, intraperitoneally). The left renal artery was exposed by retroperitoneal flank incision and dissected free of the renal vein and connective tissue. A silver clip with a lumen of $0.22 \mathrm{~mm}$ was placed around the artery for partial occlusion; in sham operations, the artery was not clipped. After 6 weeks the systolic blood pressure (SBP) was measured using the tail-cuff method in conscious rats. Only hypertensive rats (SBP above $150 \mathrm{~mm} \mathrm{Hg}$ ) were used in the experiments.

\section{Animal groups}

The mice were randomly divided into four groups of eight rats each, as follows: sham-operated control group (served as negative control); an untreated model group; rats treated with captopril (30 mg/kg per day); rats treated with MALE (75 $\mathrm{mg} / \mathrm{kg}$ per day) and rats treated with MALE (150 $\mathrm{mg} / \mathrm{kg}$ per day). Rats were treated for 6 weeks with daily oral administration of the products or the same volume of vehicle (0.9\% saline) (negative control and untreated rats). Doses of MALE were chosen in reference to doses commonly used in human and doses used in previous experiments. All rats were weighed and their blood pressure measured once weekly for 6 weeks. The animal experiment was approved by the Animal Care and Use Committee of the Third hospital of Wuhan (approval ref no. 20201004) and was carried out in compliance with the Directive 2010/63/EU on the handling of animals used for scientific purposes [12].

\section{Measurement of blood pressure}

Systolic (SBP) and diastolic blood pressure (DBP) were measured by the tail-cuff method (BP-6 noninvasive Electro-Sphygmomanometer, Chengdu Taimeng Science and Technology, Chengdu, PR China) in awaken rats. The mean of three consecutive readings was taken. The arterial systolic and diastolic blood pressure was measured at the weekend and continuous measurement was carried out three times as the average blood pressure for weeks.

\section{Assessment of the renal function}

At the last week of the experiment, the animals were placed in individual metabolic cages and acclimatized for two consecutive days before a 24-h urine collection. Creatinine and urea were measured with a commercial enzyme-linked immunosorbent assay (Nanjing Jiancheng Institute of Biological Engineering, Nanjing, China) as described by the manufacturer [13]. 
Determination of serum SOD activity and lipid peroxide level (MDA)

Serum superoxide dismutase (SOD) activity and the malondialdehyde (MDA) level were determined according to the instructions in the kit (Nanjing Jiancheng Institute of Biotechnology, Nanjing, China) as described by the manufacturer [13].

\section{Statistical analysis}

Data are presented as mean \pm standard deviation (SD), and were analyzed by one-way ANOVA followed by Tukey's multiple comparison using SPSS 16.0 software. Differences were considered statistically significant at $p<0.05$.

\section{RESULTS}

\section{Effect of MALE on the blood pressure of 2K1C hypertensive rats}

Untreated hypertensive rats had markedly higher SBP and DBP than the sham-operated rats $(p<$ $0.01)$. The hypertension was stable over 6 weeks of the experiment. In the captopril- or MALE treated groups, the blood pressure significantly $(p<0.05)$ decreased progressively over the course of the 6 weeks treatment compared with that of the untreated rats (Table 1 ).

Table 1: Effect of MALE on the blood pressure of $2 \mathrm{~K} 1 \mathrm{C}$ hypertensive rats (mean $\pm \mathrm{SD}$ )

\begin{tabular}{lccc}
\hline Group & $\begin{array}{c}\text { Dosage } \\
(\mathbf{m g} / \mathbf{k g})\end{array}$ & $\begin{array}{c}\text { SBP } \\
(\mathbf{m m H g})\end{array}$ & DBP $(\mathbf{m m H g})$ \\
\hline Normal & - & $108.7 \pm 5.5^{* *}$ & $72.8 \pm 2.6^{* *}$ \\
Control & - & $266.1 \pm 6.8$ & $122.4 \pm 3.2$ \\
Captopril & 30 & $143.4 \pm 4.5^{* *}$ & $83.5 \pm 3.5^{* *}$ \\
MALE - L & 75 & $184.2 \pm 5.4^{*}$ & $113.6 \pm 4.0$ \\
MALE -H & 150 & $148.5 \pm 4.1^{* *}$ & $87.2 \pm 3.4^{* *}$ \\
\hline
\end{tabular}

${ }^{*} P<0.05$ and ${ }^{* *} p<0.01$ versus control group; MALE-L: low dose of MALE (75 mg/kg per day); MALE-H: high dose of MALE (150 mg/kg per day)

\section{Effect of MALE on renal dysfunction in 2K1C hypertensive rats}

The levels of blood urea nitrogen (BUN) and serum creatinine (Scr) were significantly higher in the untreated rats compared to the other group $(p<0.05)$. Both MALE-L and MALE-H were able to decrease the serum BUN and Scr levels $(p<$ 0.01 ), respectively (Table 2 ).
Table 2: Effect of MALE on renal dysfunction in $2 \mathrm{~K} 1 \mathrm{C}$ hypertensive rats (mean $\pm S D$ )

\begin{tabular}{lccc}
\hline Group & $\begin{array}{c}\text { Dosage } \\
(\mathbf{m g} / \mathbf{k g})\end{array}$ & $\begin{array}{c}\text { BUN } \\
(\mathbf{m m o l} / \mathrm{L})\end{array}$ & $\mathbf{S C r}(\mu \mathrm{mol} / \mathrm{L})$ \\
\hline Normal & - & $47.7 \pm 3.8^{* *}$ & $35.6 \pm 4.3^{* *}$ \\
Control & - & $94.2 \pm 5.2$ & $78.3 \pm 5.0$ \\
Captopril & 30 & $45.3 \pm 4.8^{* *}$ & $45.6 \pm 5.8^{* *}$ \\
MALE-L & 75 & $72.6 \pm 6.2$ & $54.7 \pm 3.9$ \\
MALE-H & 150 & $58.1 \pm 3.9^{* *}$ & $38.3 \pm 3.7^{* *}$ \\
\hline${ }^{*} P<0.05$ and ${ }^{* *} p<0.01$ versus control group. MALE-L: \\
low dose of MALE (75 mg/kg per day); MALE-H: high \\
dose of MALE (150 mg/kg per day)
\end{tabular}

\section{Effect of MALE on antioxidant status in 2K1C hypertensive rats}

The plasma SOD activity in the untreated control group was significantly lower than that in the sham-operated group. The SOD activity of the MALE and captopril treated groups were significantly higher than that in the untreated control group $(p<0.01)$. The MALE and captopril-treated groups showed significantly lower MDA level $(p<0.05)$ than the untreated model group (Table 3 ).

Table 3: Effect of MALE on antioxidant status in $2 \mathrm{~K} 1 \mathrm{C}$ hypertensive rats (mean $\pm S D$ )

\begin{tabular}{lccc}
\hline Group & $\begin{array}{c}\text { Dosage } \\
(\mathbf{m g} / \mathbf{k g})\end{array}$ & $\begin{array}{c}\text { SOD } \\
(\mathbf{p g} / \mathbf{m L})\end{array}$ & $\begin{array}{c}\text { MDA } \\
(\mathbf{p g} / \mathbf{m L})\end{array}$ \\
\hline Normal & - & $167.3 \pm 5.3^{* *}$ & $3.8 \pm 1.3^{* *}$ \\
Control & - & $85.6 \pm 6.2$ & $18.9 \pm 2.4$ \\
Captopril & 30 & $125.2 \pm 4.8^{* *}$ & $7.8 \pm 1.5^{*}$ \\
MALE-L & 75 & $102.5 \pm 5.3^{*}$ & $6.5 \pm 2.0^{*}$ \\
MALE-H & 150 & $129.1 \pm 6.6^{* *}$ & $4.6 \pm 2.4^{*}$ \\
\hline${ }^{*} P<0.05$ and ${ }^{* *} p<0.01 \mathrm{versus}$ control group. MALE-L: \\
low dose of MALE (75 mg/kg per day); MALE-H: high \\
dose of MALE (150 $\mathrm{mg} / \mathrm{kg}$ per day)
\end{tabular}

\section{DISCUSSION}

The $2 \mathrm{~K} 1 \mathrm{C}$ renovascular hypertension is a classic animal model of renin-dependent hypertension. The 2K1C hypertension is an angiotensin-II (Ang-II) dependent model of hypertension where increased plasma and intrarenal Angll concentrations [14,15], enhanced production and systemic delivery of Ang-II by the clipped kidney, form the basic endocrine disturbance [16]. The endothelin (ET) system and RAAS are two of the most potent vasopressor mechanisms identified to date and in conditions where both systems are activated, their interrelationships have been proposed to contribute to the development of hypertension [17].

Previous reports showed that blood pressure regulation is dependent on the relationship between the ET system and RAAS [18]. 
The active component of the RAAS is Ang-II, which is a potent vasoconstrictor and the mechanism of RAAS-induced hypertension has generally been attributed to the direct vasoconstrictor effects of Ang-II and the mineralocorticoid effects of aldosterone. Ang-II can also elevate blood pressure by augmenting noradrenaline release from sympathetic nerve endings in the vasculature [19] by increasing secretion of potent vasoconstrictor ET-1.

A recent hypothesis pointed out a possible role of oxidative stress as a key player in the pathogenesis of insulin resistance, cell dysfunction, and hypertension [20] and many mechanisms have been implicated in processes underlying oxidative stress-mediated hypertension. The relationship between the development of hypertension and the increased bioavailability of ROS or decreased antioxidant capacity, or both, have been demonstrated in many experimental models of hypertension as well as in human hypertension [21]. These findings are based, in general, on increased levels of biomarkers of lipid peroxidation and oxidative stress [22]. Reports suggest that oxidative damage and proinflammatory processes may precede full-blown hypertension [23]. As malondialdehydes (MDA) are a class of terminal lipid peroxidation metabolites, determination of their content can directly reflect lipid peroxidation levels. On the other hand, SOD is a natural antioxidant enzyme which can remove superoxide anion radicals in vivo to maintain the production of free radicals in the body and clear the dynamic equilibrium of a metal enzyme. Therefore, protection of the endothelial function and reduction of free radical damage in the treatment and prevention of hypertensive target organ damage can have a far-reaching significance. The results suggest that MALE may play a key role in improving endothelial lipid oxidative damage and high blood pressure to the same extent as captopril.

\section{CONCLUSION}

The findings of this study demonstrate that MALE exhibits significant antihypertensive effect by inhibiting endothelin-converting enzyme and via its antioxidant activity. It can therefore be potentially developed into a new drug in humans.

\section{DECLARATIONS}

\section{Conflict of interest}

No conflict of interest is associated with this work.

\section{Contribution of authors}

We declare that this work was done by the authors named in this article and all liabilities pertaining to claims relating to the content of this article will be borne by the authors. Sheng-li Pei designed the study, Fang Kan performed the experiments, and Chun-jiang Yue revised the manuscript.

\section{Open Access}

This is an Open Access article that uses a funding model which does not charge readers or their institutions for access and distributed under the terms of the Creative Commons Attribution License (http://creativecommons.org/licenses/by/ 4.0) and the Budapest Open Access Initiative (http://www.budapestopenaccessinitiative.org/rea d), which permit unrestricted use, distribution, and reproduction in any medium, provided the original work is properly credited.

\section{REFERENCES}

1. Ma $H Y$, Zhao $Z T$, Wang $L J$, Wang $Y$, Zhou QL, Wang $B X$. Comparative study on anti-hypercholesterolemia activity of diosgenin and total saponin of Dioscorea panthaica. Zhongguozhong yaozazhi 2002; 27: 528-531.

2. Lee SC, Tsai CC, Chen JC, Lin JG, Lin CC, Hu ML, Lu S. Effects of Chinese yam on hepato-nephrotoxicity of acetaminophen in rats. Acta Pharmacol Sin 2002; 23:503-508.

3. Hou WC, Hsu FL, Lee MH. Yam (Dioscorea batatas) tuber mucilage exhibited antioxidant activities in vitro. Planta Med 2002; 68: 1072-1076.

4. Liu YH, Lin YS, Liu DZ, Han CH, Chen CT, Fan M, Hou WC. Effects of different types of yam (Dioscorea alata) products on the blood pressure of spontaneously hypertensive rats. Bios Biotechnol Biochem 2009; 73 : 1371-1376.

5. Bidani AK, Griffin KA. Pathophysiology of hypertensive renal damage: implications for therapy. Hypertension 2004; 44: 595-601.

6. Navar LG, Zou L, Von Thun A, Wang CT, Imig JD, Mitchell $K D$. Unraveling the mystery of Goldblatt hypertension. News Physiol Sci 1998; 13: 170-176.

7. Laragh $\mathrm{JH}$. On the mechanisms and clinical relevance of one-kidney, one-clip hypertension. Am J Hypertens 1991; 4: 541-545.

8. Pinto YM, Paul M, Ganten D. Lessons from rat models of hypertension: from Goldblatt to genetic engineering. Cardiovasc Res 1998; 39: 77-88.

9. Al-Qattan KK. Different levels of hypertension induce opposite diuretic behaviors from the non-clipped kidney in the rat two-kidney, one-clip model. Kidney Blood Press $R$ 2001; 24: 44-51. 
10. Morishita R, Higaki J, Okunishi H, Nakamura F, Nagano M, Mikami $H$, Ishii K, Miyazaki M, Ogihara T. Role of tissue renin angiotensin system in two kidney, one-clip hypertensive rats. Am J Physiol 1993; 264: 510-514.

11. Carvalho $M H$, Fortes $Z B$, Nigro $D$, Oliveira $M A$, Scivoletto $R$. The role of thromboxane $A 2$ in the altered microvascular reactivity in two-kidney, one clip hypertension. Endothelium 1997; 5: 167-178.

12. European Commission [homepage on the internet]. Directive 2010/63/EU on the protection of animals used for scientific purposes [cited 2013 Jan 16]. Available from http://ec.europa.eu/environment/chemicals/lab_ animals/legislation_en..htm.

13. QY Ding, Yu Zhang, Li Ma, YG Chen, JH Wu, HF Zhang, Xiong Wang. Inhibiting MAPK14 showed antiprolactinoma effect. BMC Endocrine Disorders 2020; 20:138.

14. Al-Qattan KK, Khan I, Alnaqeeb MA, Ali $M$. Thromboxane-B2, prostaglandin-E2 and hypertension in the rat 2-kidney 1-clip model: a possible mechanism of the garlic induced hypertension. Prostag Leukotr Ess 2001; 64: 5-10.

15. Briones AM, Touyz RM. Oxidative stress and hypertension: Current concepts. Curr Hypertens Rep 2010; 12: 135-142.
16. Haddad JJ. Antioxidant and prooxidant mechanisms in the regulation of redox(y)-sensitive transcription factors. Cell Signal 2002; 14: 879-897.

17. Ardanaz N, Pagano PJ. Hydrogen peroxide as a paracrine vascular mediator: regulation and signaling leading to dysfunction. Exp Biol Med 2006; 231: 237251.

18. Liochev SI, Fridovich I: The effects of superoxide dismutase on H2O2formation. Free Radical Bio Med 2007; 42: 1465-1469.

19. Umar A, Guzelnur I, Yimin Y, Kerim P, Tohti I, Berké B. Antihypertensive effects of Ocimum basilicum $L$. (OBL) on blood pressure in renovascular hypertensive rats. Hypertens Res 2010; 33: 727-730.

20. Iversen BM, Heyeraas KJ, Sekse I, Andersen KJ, Ofstad J. Autoregulation of renal blood flow in two-kidney, oneclip hypertensive rats. Am J Physiol 1986; 25: 245-250.

21. Iversen BM, Morkrid L, Ofstad J. Afferent arteriolar diameter in DOCA-salt and two-kidney one-clip hypertensive rats. Am J Physiol 1983; 245: 755-762.

22. Ploth DW, Fitzgibbon W. Pathology of altered renal function in renal vascular hypertension. Am J Kidney Dis. 1994; 24: 652-659.

23. Rossi GP, Sacchetto A, Cesari M, Pessina AC. Interactions between endothelin-1 and the reninangiotensin-aldosterone system. Cardiovasc Res 1999; 43: $300-307$. 